\title{
Pilonidal sinüs tedavisinde primer onarım gerçekten terkedilmesi gereken bir yöntem midir?
}

\author{
Pilonidal sinus disease treatment; Is primary repair method is really \\ dispensable?
}

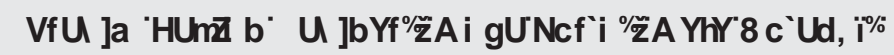

${ }^{1}$ Hitit Üniversitesi Tıp Fakültesi Genel Cerrahi Ana Bilim Dalı

\section{ÖZET}

\section{Giriș:}

Pilonidal sinüs (PS) sakrokoksigeal bölgenin sık karşılaşılan benign seyirli kronik bir hastalığıdır. Hastalığın etiyolojisinde kıl foliküllerinin oluşturduğu yabancı cisim reaksiyonu en çok kabul gören teoridir. Günümüzde çeşitli cerrahi yöntemler uygulanmasına rağmen halen ideal bir tedavi yöntemi yoktur. Bu çalışmada PS eksizyonu sonrası primer ve limberg flep ile yapılan onarım karşılaştııılmıştır.

\section{Gereç ve Yöntemler:}

2005-2012 yılları arasında kliniğe pilonidal sinüs nedeni ile başvuran olgular retrospektif olarak incelendi. Bu yıllar arasında 184 hastaya primer onarım yapilırken 192 hastaya limberg flep onarımı yapıldı. Akut enfeksiyonu olan ve sinüs eksizyonu yapılmadan sadece apse drenajı yapılan hastalar çalışmaya dâhil edilmedi. Hastalara ulaşılarak kontrolleri yapıldı. Veriler istatistiksel olarak değerlendirildi.

\section{Bulgular:}

Ameliyat ve hastanede kalış süresi limberg flep onarımı yapılan hastalarda anlamlı olarak yüksek bulundu $(p<0,05)$. Cerrahi alan enfeksiyonu, yara ayrışması, postoperatif ilk defekasyon sırasında ağrı ve nüks açısından anlamlı bir fark saptanmazken $(p>0,05)$, kozmetik kaygı, uzun dönemde yara yerinde hissizlik ve kaşıntı limberg flep onarımı yapılan hastalarda anlamlı derecede yüksek bulundu $(p<0,05)$.

\section{Sonuç:}

Sonuç olarak, pilonidal sinüs tedavisinde çok çeşitli konservatif ve cerrahi yöntemler kullanılmaktadır. Fakat bu tedavi yöntemlerinin hiç biri tam olarak kür sağlamayıp nüksü engelleyememektedir. Kozmetik kayıpların daha az olduğu, hastanın his kaybının daha nadir olduğu ve diğer yöntemlere nazaran daha az invaziv bir işlem olan primer onarım yöntemi güncel pratikte halen tercih edilebilir.

Anahtar Kelimeler: pilonidalsinüs, primeronarım, limberg flep

\section{ABSTRACT}

\section{Objective:}

Pilonidal sinus disease (PSD) is a benign disease caused by hair follicles in sacrococcygeal region. Despite the use of different methods in treatment, there is no consensus reached for treatment modalities. In this study we compared the primary repair and limberg flap method.

Material and Methods:

In this study, 376 PSD patients who underwent surgery in our clinic between $2005-2012$ were analyzed retrospectively.184 of these patients managed with primary repair and 192 with limberg flap. Patients who have acute enflamation symptoms and abcess were excluded. Patients evaluated rertospectively. All data examined for statistical analysis.

Results:

Surgery time and hospital stay were significantly higher in patients who underwent Limberg flap repair $(p<0,05)$. There were no statistically difference about surgical site infection, wound dehissence, first defecation pain and recurrence between two groups $(p>0,05)$. But cosmetic care, surgical site paresthesia were found higher in limberg flap group $(p<0,05)$.

\section{Conclusion:}

Many methods have been defined for repair of the pilonidal disease. However, none of these treatments can not prevent recurrence and fully cure. Primary repair method is still can be preferred because of its cosmetic results, minimally invasive procedure.

Keywords: pilonidal sinus disease, primary repair, limberg flap
Corresponding Author: Ibrahim Tayfun Şahiner

Address: Hitit Üniversitesi Tıp Fakültesi Genel Cerrahi Ana Bilim Dalı Bahçelievler Mah. Çamlık Cad. No: 219030 Çorum

E-mail: tayfunsahiner@gmail.com
Başvuru Tarihi/Received: 30-12-2015

Kabul Tarihi/Accepted: 05-04-2016 


\section{Giriş}

Pilonidal sinüs sıklıkla sakrokoksigeal bölgede natal kleft hattı boyunca görülen kronik seyirli benign bir hastalıktır. Hastalığın etiyolojisi üzerine konjenital ve edinsel teoriler bulunmaktadır. Konjenital teoride natal kleft hattı boyunca bir skuamöz epitel traktının bulunduğu düşünülür. Edinsel teoride ise Bascom ve Karydakis'in çalışmalarının ön plandadır ve bu edinsel teori son zamanlarda en çok kabul gören teoridir (1). Edinsel teorideki bu her iki görüşte de kıl foliküllerinin oluşturdukları reaksiyonlar pilonidal sinüsün ana nedenini oluşturduğu kabul edilmiştir. İntergluteal bölgede mikro travmaların tetiklediği mikro apseler zamanla akıntılı ve ağrılı büyük odaklar şeklinde kendini gösterir. Pilonidal sinüs kistleri içerisindeki kıllar hem yabancı cisim reaksiyonu hem de kronik irritasyona neden olarak kronik akıntı veya apselere neden olmaktadır. Kılların pilonidal sinüs patogenezinde önemli bir yer tutmasına rağmen her pilonidal sinüs kisti içerisinde de kıl bulunmamaktadır. Bu durum \% 25-50 oranında görülmektedir (2). Pilonidal sinüs subkutan alanda yaklaşık 1-5 cm'lik traktlar şeklinde bulunur. Pilonidal sinüslerde oluşan sekonder traktlar genellikle kranial doğrultuda seyrederken kaudale uzanım daha az görülür. Kaudal uzanımlar perianal fistül traktları ile karıştırılabilmektedir. Hastalık benign bir seyirde olmasına rağmen nadiren malign transformasyonlar görülebilmektedir (3).

Pilonidal sinüs hiçbir klinik vermeden tespit edilebileceği gibi akut veya kronik apse formasyonu ile de kendisini gösterebilir. Kronik vakalar intergluteal sulkusta akıntılı sinüs ağızlarıyla karakterize bir görünüm oluşturmaktadır. Pilonidal sinüs kıl folikülü yoğun olan, kişisel hijyeni kötü olan, derin intergluteal sulkusu olan, uzun süreli oturarak çalışan, obez ve erkek cinsiyette daha sık görülen bir durumdur (4).

Akut pilonidal apselerin tedavisinde orta hattın dışındaki bir alandan drenaj uygulanmalı, apse kavitesi ya kürete edilmeli ya da etkili bir şekilde kavite içeriğinin boşaltılması sağlanmalıdır. Kronik vakalarda seçilecek cerrahi yönteme hastadaki pilonidal sinüsün yaygınlığı da göz önünde bulundurularak karar verilmelidir. Pilonidal sinüs tedavisinde çok farklı yöntemler kullanılmasına rağmen cerrahisinde henüz karar birliğine varılmış bir yöntem bulunmamaktadır. Uygulanan farklı tedavi yöntemlerinin \% 3-46 oranında değişen nüks oranları bulunmaktadır (5). Literatürde flep tekniklerinin kullanıldığı pilonidal sinüs cerrahisinde nüks oranlarının daha düşük olduğu belirten yayınlar mevcuttur (6). Primer onarım ise küçük ve sekonder uzanımları olmayan pilonidal sinüslerde kozmetik açısından daha iyi bir sonuç elde etmek için tercih edilmektedir.

Bu çalışmada pilonidal sinüs eksizyonu sonrası primer onarım ve limberg flep ile rekonstrüksiyon sonuçları karşılaştırılmıştır.

\section{GEREÇ VE YÖNTEMLER}

Sağlık Bakanlığı Hitit Üniversitesi Çorum Eğitim ve Araştırma Hastanesi genel cerrahi kliniğine 2005 - 2012 yılları arasında başvuran ve cerrahi tedavi yapılan pilonidal sinüs hastaları retrospektif olarak veri tabanından taranmıştır. Ulaşılan 376 hasta şikâyetlerinin varlığı ve nüks açısından kontrole çağrılmıştır. Pilonidal sinüs nedeni ile sinüs eksizyonu yapılıp sonrasında primer onarım yapılan 184 hasta ve limberg flep işlemi uygulanan 192 hasta çalışmaya dahil edilmiştir. Veri tabanından elde edilen bilgiler ışığında bütün hastalara anestezi indüksiyonu sırasında profilaktik olarak intravenöz $1 \mathrm{gr}$ Sefazolin sodyum uygulanmış olup hastaların tümüne spinal anestezi altında cerrahi uygulanmıştır. Hastalar poliklinik 
başvurularına göre randomize edilmiştir. Çalışmaya alınan hastaların ortalama yaşı sırasıyla primer onarım yapılan grupta 25 (17-43), limberg yapılan grupta ise 27 (18-50) olarak bulunmuştur. Hastaların operasyon süreleri, hastanede kalış süreleri, postoperatif dönemde defekasyon sırasında ağrısı, cerrahi alan enfeksiyonu, yara ayrışması ve flep nekrozu, uzun dönemde nüks, kozmetik endişe ve sonuçları veri tabanından elde edilen bilgiler ışığında değerlendirildi. Non parametrik verilerin analizi için Mann Whitney $U$ testi kullanıldı. Parametrik verilerde ise frekans, ortalama değer ölçümleri yapıldı. Verilerin istatistiksel analizi yapıldı. $p<0,05$ olması anlamlı kabul edildi.

\section{BULGULAR}

Yapılan çalışmada limberg flep onarımı yapılan 192 hastanın ortalama hastanede yatış süresi 3,2 gün (1-5 gün) ve ortalama ameliyat süresi 55 dakika (38-85) olarak bulunmuştur. 168 hastada $(\% 87,5)$ ilk defekasyon sırasında ağrı gözlenmemiştir. Limberg flep onarımı yapılan hastaların $18^{\prime}$ inde $(\% 9,37)$ cerrahi alan enfeksiyonu, 2 'sinde $(\% 1,04)$ yara ayrışması, görülürken hiçbir hastada flep nekrozu görülmemiştir. Limberg flep onarımı yapılan hastaların ortalama 18 aylık takiplerinde (12-24 ay) 6 olguda $(\% 3,12)$ nüks tespit edilmiştir. Yara yerinde his kaybı ve kaşıntı 45 hastada $(\% 23,43)$, kozmetik endişe ise 126 hastada (\%65, 62) görülmüştür (Tablo 1).

Tablo 1: Her iki grubun karşılaştırılması

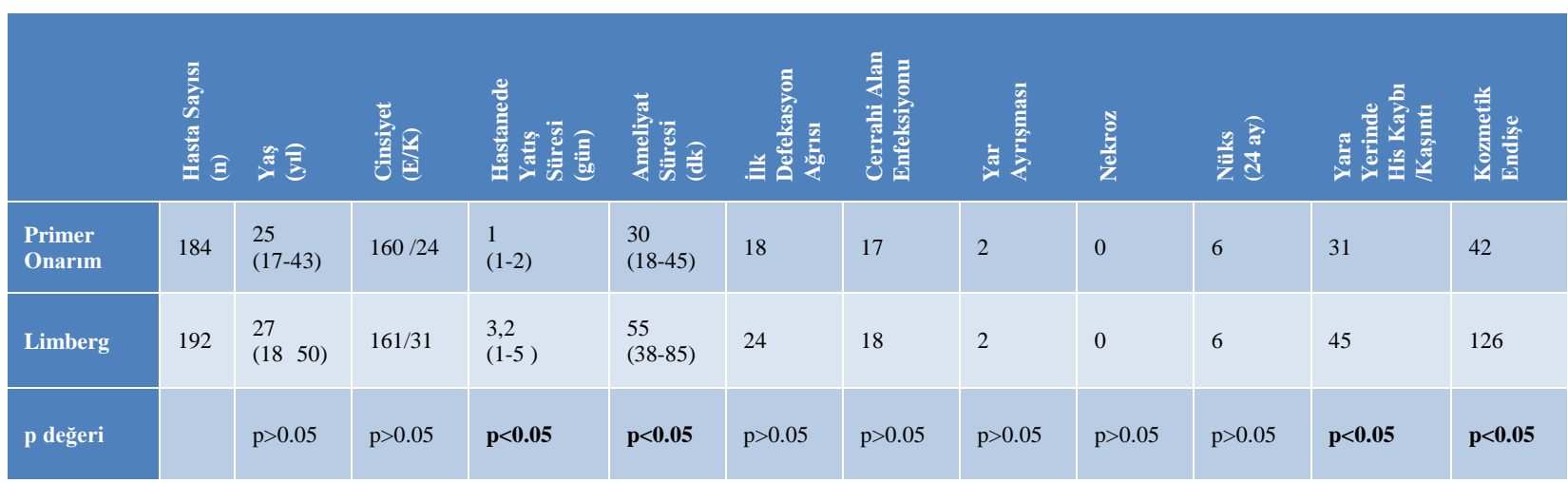

Pilonidal sinüs için eksizyon ve primer onarım yapılan 184 olguda ise ortalama hastanede yatış süresi 1 gün (1-2) ve ortalama ameliyat süresi 30 dakika (18-45) olarak bulunmuştur. Hastaların 18'inde (\% $9,78)$ ilk defekasyon sırasında ağrı saptanmıştır. Primer onarım yapılan hastaların 17 'sinde $(\% 9,23)$ cerrahi alan enfeksiyonu, 2'sinde $(\% 1,08)$ yara yerinde ayrışma saptanmıştır. Primer onarım yapılan hastaların ortalama 18 aylık takiplerinde (12-24 ay) 6 olguda (\% 3,26) nüks saptanmıştır. Yara yerinde his kaybı ve kaşıntı 31 hastada $(\% 16,84)$, kozmetik endişe ise 42 hastada $(\% 22,82)$ görülmüştür (Tablo 1).

Her iki yöntem karşılaştırıldığında limberg flep onarımı yapılan grupta hastanede kalış süreleri ve ortalama ameliyat süreleri istatistiksel olarak anlamlı derecede yüksek bulunmuştur $(p<0,05)$. ilk defekasyon sırasında ağrı, cerrahi alan enfeksiyonu, yara ayrışması ve nüks gelişimi açısından istatistiksel olarak anlamlı bir fark saptanmazken, yara yerinde his kabı, kaşıntı ve kozmetik endişe primer onarım yapılan grupta istatistiksel olarak anlamlı derecede daha az görülmüştür $(p<0,05)$. 


\section{TARTIŞMA}

Pilonidal sinüs 1833 yılında Herbert Mayo tarafından tariflenmiş benign bir klinik durumdur. Hastalık zaman içerisinde farklı yöntemlerle tedavi edilmeye çalışılmış, farklı etiyolojik faktörler üzerinde durulmuş ancak hiç birisinde fikir birliği sağlanamamıştır. Pilonidal sinüs vücudun farklı bölgelerinde görülebilmesine rağmen en sık kıl foliküllerinin yoğun olduğu intergluteal sulkusta natal kleft hattı boyunca görülmektedir. Hastalığın tedavisinde cerrahi olmayan yöntemlerden geniş eksizyon yapılan cerrahi yöntemlere kadar değişen farklı metotlar bulunmaktadır. Klinikte en sık kullanılan yöntemler primer onarım veya flep teknikleridir. Flep tekniklerinden Limberg Flep yöntemi uygulamasının kolay olması ve geniş sinüs ağızları olan vakalarda etkilenen dokuların tamamının çıkarılması sonucu oluşan defektin kolayca kapatılabilmesine olanak sağlaması açısından sıklıkla tercih edilen bir yöntemdir.

Pilonidal sinüs cerrahisinde ideal cerrahi yöntem maliyeti düşük, uzun süre hastanede kalmayı gerektirmeyen, ağrının en az olduğu, hastanın erken dönemde çalışma hayatına dönmesine olanak sağlayan ve düşük nüks oranı olan yöntemdir. Bu her pilonidal sinüs hastası için mümkün olamamakta hastalığın yaygınlığına bağı olarak optimum şartlar her zaman sağlanamamaktadır. Uygulanan her tekniğin avantaj ve dezavantajları bulunmaktadır. Primer onarım yapılan pilonidal sinüslerde operasyon süreleri ve hastanede kalış süreleri diğer yöntemlere oranla oldukça azdır fakat literatürde nüks oranlarının daha fazla olduğunu bildiren çalışmalarda mevcuttur $(7,8)$. Buna rağmen küçük ve komplike olmayan olgularda Kozmetik'te düşünülerek primer onarım pilonidal sinüs cerrahisinde çoğu merkezde sıklıkla hem hasta hem de cerrah tarafından tercih nedeni olmaktadır.

Yapılan bu çalışmada primer onarım yapılan hastalarda operasyon süresi ve hastanede kalış süresi literatür ile uyumlu olarak limberg flep onarımına göre daha kısa bulunmuştur. Bunda işlemin flep yöntemine göre daha basit oluşu ve çıkarılan doku miktarının azlığı önemli faktörlerdir. Cerrahi alan enfeksiyonu ağrı ve yara yerinde ayrışma açısından flep onarımı ile arasında anlamlı bir fark saptanmamıştır.

Literatürde de limberg flep yöntemi ile yapılan onarımlarda nüks oranlarının daha düşük olduğunu vurgulayan yayınlar bulunsa da; $(9,10)$ bu çalışmada da limberg flep yönteminin nüks oranının primer onarıma göre herhangi bir üstünlüğü olmadığı tespit edilmiş ve postoperatif erken dönemde hasta konforunun primer onarım yapılan bireylerde daha yüksek olduğu izlenmiştir. Postoperatif dönemde kozmetik problemlerin, yara yerinde kaşıntı ve his kaybının limberg flep onarımı yapılan bireylerde daha fazla görülmesi, cerrahi alanın daha büyük olması çıkarılan doku miktarının daha fazla olması ile açıklanabilir. Primer onarım yapılan olgularda insizyon ve iyileşme alanı çoğu zaman intergluteal sulcuslar tarafından kapatıldığı için kozmetik açıdan çok daha iyi sonuçlar elde edilmiştir. Hasta memnuniyeti diğer yöntemlere kıyasla daha fazla olmaktadır.

Sonuç olarak, nüks oranlarının iddia edilenden daha düşük olması, hasta konforu, kozmetik sonuç ve memnuniyetinin daha yüksek olması nedeniyle çok komplike olmayan pilonidal sinüsün cerrahi tedavisinde primer onarımın tercih edilmesi gerektiğini düşünüyoruz. Flep tekniklerinin ancak komplike pilonidal sinüs cerrahisinde tercih edilmesi uygun olacaktır. Tüm yazarlar bu çalışma ile ilgili finansal destek almadıklarını ve herhangi bir çıkar çatışma / Çakışması olmadığını beyan eder. 


\section{REFERANSLAR}

1. Chintapatla S, Safarani N, Kumar S, Haboubi N. "Sacrococcygeal pilonidal sinus: historical review, pathological insight and surgical options", Tech Coloproctol. 2003 Apr;7(1):3-8.

2. Bascom J, Bascom T. "Failed pilonidal surgery: new paradigm and new operation leading to cures.", Arch Surg. 2002 Oct;137(10):1146-50; discussion 1151

3. Malek MM, Emanuel PO, Divino CM. "Malignant degeneration of pilonidal disease in an immunosuppressed patient: report of a case and review of the literature.",Dis Colon Rectum. 2007 Sep;50(9):1475-7.

4. da Silva JH."Pilonidal cyst: cause and treatment. "Dis Colon Rectum. 2000 Aug; 43(8):1146-56.

5. Mentes $O$, Bagci $M$, Bilgin $T$, Ozgul O, Ozdemir $M$. "Limberg flap procedure for Pilonidal sinus disease: results of 353 patients." Langenbecks Arch Surg. 2008 Mar; 393(2):185-9. Epub 2007 Sep 22
6. Schoeller T, Wechselberger G, Otto A, Papp C. "Definite surgical treatment of complicated recurrent pilonidal disease with a modified fasciocutaneous V-Y advancement flap." Surgery. 1997 Mar; 121(3):258-63.

7. Mahdy T. "Surgical treatment of the pilonidal disease: primary closure or flap reconstruction after excision." Dis Colon Rectum. 2008 Dec; 51(12):1816-22. Epub 2008 Oct 21.

8. Cihan A, Mentes BB, Tatlicioglu E, Ozmen S, Leventoglu S, Ucan BH."Modified Limberg flap reconstruction compares favourably with primary repair for pilonidal sinus surgery." ANZ J Surg. 2004 Apr; 74(4):238-42.

9. Osmanoglu G, Yetisir F. "Limberg flap is better for the surgical treatment of pilonida sinus. Results of a 767 patients series with an at least five years follow-up period."Chirurgia (Bucur). 2011 Jul-Aug; 106(4):491-4.

10. Topgül K, Ozdemir E, Kiliç K, Gökbayir H, Ferahköşe Z."Long-term results of limberg flap procedure for treatment of pilonidal sinus: a report of 200 cases."Dis Colon Rectum. 2003 Nov; 46(11):1545-8 